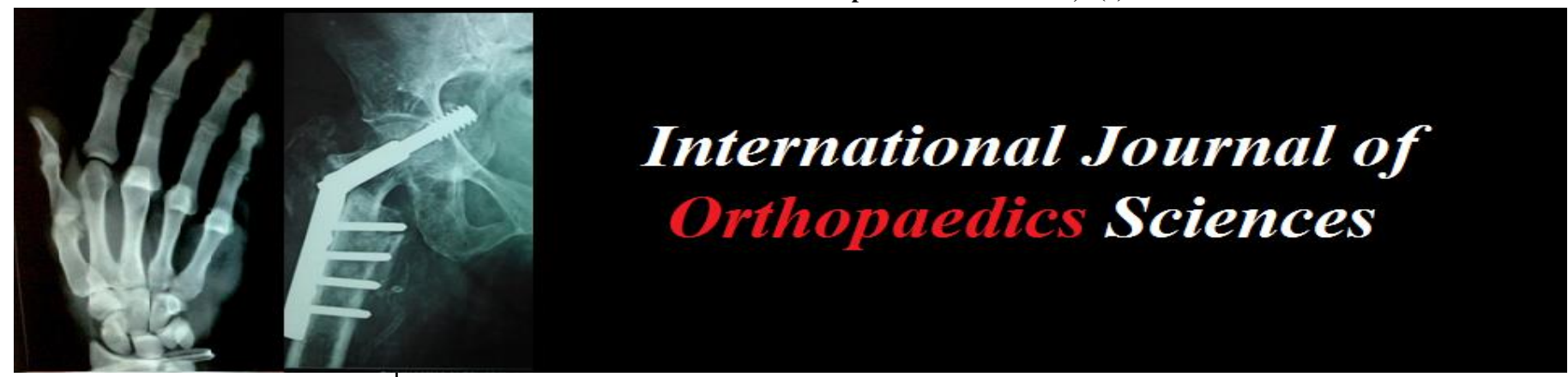

ISSN: $2395-1958$

IJOS 2019; 5(2): 39-46

(C) 2019 IJOS

www.orthopaper.com

Received: 18-02-2019

Accepted: 19-03-2019

Dr. Ravi Kiran Kakumanu Assistant Professor, NRI Institute of Medical Sciences, Sangivalasa, Visakhapatnam, Andhra Pradesh, India

Dr. Ravi Teja Kunadharaju

Assistant Professor, NRI

Institute of Medical Sciences,

Sangivalasa, Visakhapatnam,

Andhra Pradesh, India

Dr. Mrudula Beesetty

M.B.B.S, NRI Institute of

Medical Sciences, Sangivalasa,

Visakhapatnam, Andhra

Pradesh, India

Dr. Dinesh Golla

Assistant Professor, NRI

Institute of Medical Sciences,

Sangivalasa, Visakhapatnam,

Andhra Pradesh, India
Correspondence

Dr. Ravi Teja Kunadharaju

Assistant Professor, NRI

Institute of Medical Sciences,

Sangivalasa, Visakhapatnam,

Andhra Pradesh, India

\section{Ease of doing proximal femoral nailing in lateral position in the management of peri-trochanteric femoral fractures in adults: A prospective study}

\author{
Dr. Ravi Kiran Kakumanu, Dr. Ravi Teja Kunadharaju, Dr. Mrudula \\ Beesetty and Dr. Dinesh Golla
}

DOI: https://doi.org/10.22271/ortho.2019.v5.i2a.10

\section{Abstract}

Introduction: Intertrochanteric fractures are among the most common pei-trochanteric fractures encountered in orthopaedic practice. Most of the hip fractures are managed in supine position on a fracture table with foot attached to foot plates and biplanar fluoroscopy supervision under c-arm. But this procedure has its own difficulties in managing especially comminuted peri-trochanteric fractures, where in different fragments and segments are being pulled by strong muscles around hip, and getting good reduction and satisfactory alignment is difficult due to displaced bony fragments being held in traction on fracture table and cannot be manipulated easily. This leads to prolonged operative time, opening of fracture site, increased bleeding, and increased chances of infection and over all increased anaesthesia time adding up to risk factors. The purpose of this study was to demonstrate the technique of surgery as well as to report how these difficulties can be overcome by using long Proximal Femoral Nail in complex comminuted unstable trochanteric fractures in lateral position on an ordinary radiolucent top table without fracture table.

Materials and Methods: 30 cases of peri-trochanteric fractures with or without comminution were operated in lateral position on simple ordinary radioluscent top table with lesser attachments and adjustments to operating table during the study duration were included in the study. We used long Proximal Femur Nail (PFN) (length more than $25 \mathrm{cms} 34,36,38,40 \mathrm{cms}$ long) to fix these fractures.

Results: In the present study, age group of patients was $60 \mathrm{yrs}$ to $78 \mathrm{yrs}$. Male patients $(60 \%)$ were more than female patients (40\%) An average of less than $150 \mathrm{ml}$ in closed surgery and $350 \mathrm{ml}$ in Open reduction cases. The average operative time for all cases was 80 minutes. Union time varied from 14 weeks in simple fractures to 26 weeks in comminuted fractures. Clinical function of hip and knee was excellent with full range of movements. Overall excellent to good results were achieved in $90 \%$ cases.

Conclusions: The lateral decubitus position provides easy identification of entry point, a shorter operation time, less of hospital stay, blood loss, number of intraoperative X-ray, incision length and outof-bed activity time Reduction and fixation of proximal femoral fractures in the lateral position with fluoroscopy in the anteroposterior view for small set ups and rural hospitals that lack a fracture table or advanced fluoroscopic devices may be executable and probably safe.

Keywords: Long PFN, Trochanteric fracture, Lateral decubitus position, Fluoroscopy, Ordinary operating table

\section{Introduction}

Peritrochanteric fractures includes fractures from extra capsular part of neck to a point $5 \mathrm{~cm}$ distal to lesser trochanter. Intertrochanteric fractures are among the most common fractures encountered in orthopaedic practice. Intertrochanteric fractures are defined as "fractures involving upper end of femur through and in between both trochanters with or without extension into upper femoral shaft." Intertrochanteric fractures are one of the most common fractures in elderly osteoporotic population ${ }^{[1]}$. They are 3 or 4 times more common in elderly women over 60 years of age who are osteoporotic, in whom trivial trauma is the most common mode of injury ${ }^{[2-3]}$. The annual global number of hip fractures is expected to exceed 7 million in the next 40 to 50 years ${ }^{[4-5]}$. Intertrochanteric and subtrochanteric fractures make up of about $50 \%$ of hip fractures ${ }^{[6]}$. There are different methods and implants for managing these fractures in different positions to enumerate 
a) supine position on fracture table b) In lateral position on ordinary table and c) prone position with extended posterolateral exposure ${ }^{[7-8]}$. Kuntscher introduced lateral position for intramedullary nailing of femur shaft fractures in 1940, later Davis and Frymoyer described for management of intertrochanteric and subtrochanteric fractures with Jewett nail plate in 1969. Rohilla ${ }^{[9]}$ et al. reported that 41 patients of femoral shaft fractures had closed intramedullary nailing in lateral decubitus position without fracture table or image intensifier, and results suggested that this technique a safe and reliable alternative to achieve closed locked intramedullary nailing without the use of image intensifier and fracture table. Kim et al. have reviewed that patients with femur fractures were treated with closed femoral intramedullary nailing in lateral decubitus position on radiolucent routine table, and results indicated that closed femoral intramedullary nailing in lateral decubitus position with the aid of intraoperative skeletal traction is safe and an effective technique with a low incidence of complications compared to the use of fracture table ${ }^{[10]}$.

Majority of the hip fractures are operated on fracture table in supine position. But fixing the patient on the fracture table is cumbersome and more time-consuming. Positioning of obese patient on a fracture table and securing to footplates of fracture table is still more difficult because of pendulous abdomen and gluteal folds falling by the side. In the case of failed closed reduction, exposure of the fracture site for open reduction is difficult, because the patient is in the supine position and the hip is in traction while extended. In certain instances, operating surgeon finds some difficulty in the operative field to tackle such as haemostasis, retraction of soft tissues \& greater assistance is required in such conditions. When there is associated ipsilateral fractures down below in leg and opposite limb fractures positioning a polytraumatized patient on fracture table becomes all the more difficult ${ }^{[12]}$. The possibility of side effects of fracture table including injuries like pudendal nerve neuropraxia \& perennial pressure sore can be considered ${ }^{[13-14]}$. All these complications can be minimized with lateral decubitus position. The purpose of this study was to demonstrate the technique of surgery using long PFN in complex comminuted unstable trochanteric fractures in lateral position on an ordinary radiolucent top table without fracture table.

\section{Materials and Methods}

2.1. General Data: This prospective study consists of 30 elderly patients with low-energy peri-trochanteric fractures, who were treated with internal fixation using PFN at Department of Orthopedics, NRI institute of medical sciences from June2017 to September 2018. Out of 30 cases, 18 patients were males and 12 patients were females. As soon as the patient with suspected trochanteric fracture was seen in the casualty, necessary clinical and radiological evaluation was done and the patient was immobilized using skeletal traction (upper tibial pin). All the patients were evaluated with routine investigation before surgery and fitness for surgery and consent for the operation were taken. All the patients were operated in lateral position on simple ordinary radiolucent top table with lesser attachments and adjustments to operating table. Long PFN (length more than $25 \mathrm{cms} 34,36$, $38,40 \mathrm{cms}$ long) was used to fix these fractures in majority of the cases.

2.2. Inclusion criteria: (1) Adult men and women of age 60 years old and/or older (2) Trochanteric fracture confirmed with either by radiographs or computed tomography (3) Fresh fracture occurred within 21 days (4) Those who are ambulatory prior to fracture; (5) Those who signed informed Consent by themselves or their immediate family members; (6) patients who have clear consciousness \& without any medical co-morbidities.

2.3. Exclusion criteria: All those patients who have (1) Old fractures; (2) Pathologic fractures (3) Open fractures (4) Multiple injuries or multiple fractures and (5) Medical comorbidities.

2.4. Surgical technique: All patients were operated under spinal and/or epidural anaesthesia. The patient was placed in lateral position on a radiolucent table with adduction of the affected limb by 10 to 15 degrees and the unaffected limb was partially flexed at the hip and the knee to prevent it from interfering with $\mathrm{C}$-arm. The advantage of lateral position is easy identification of greater trochanter and entry point, useful in obese patients, easy to achieve reduction by open reduction technique and ease in placing distal locking screws. The tip of the greater trochanter was located by palpation and a longitudinal incision was taken. The incision started 4 to 5 cms proximal to the tip of the greater trochanter. A parallel incision was made in the fascia lata and the gluteus medius was split in line with its fibers. Tip of the greater trochanter was exposed. In some unstable fractures the fracture was open reduced and stabilized with a circalage wire or interfragmentary screws before proceeding with the nail insertion. In other cases, however, the fracture was closed reduced by traction and gentle rotation and the nail inserted. The entry site is at the tip of the greater trochanter at its centre as confirmed by $\mathrm{C}$-arm in both antero-posterior and lateral views. The entry site is opened with an awl. The guide wire is then inserted in the centre of the medullary cavity. Over the guide wire flexible reamer is inserted through the tissue protecting sleeve and serial reaming is done. Reaming was done starting from $7 \mathrm{~mm}$ to $12 \mathrm{~mm}$ in the distal segment to fit thicker diameter nail. After confirming satisfactory fracture reduction, the appropriate sized nail as determined preoperatively was assembled to the insertion handle and inserted manually as far as possible. In cases where satisfactory reduction was not possible, open reduction was done. The nail was then inserted completely in the femur till the proximal tip was flush to the tip of the greater trochanter. A required anteversion of neck was made by adjusting long PFN jig accordingly. To visualize lateral view of neck, the thigh is gently flexed, abducted and externally rotated. This gives a lateral view of neck portion and placement of guide wires in neck and head portion. The placement of guide wire should be central or poster central. Rotational alignment of fracture is assessed by checking patella is facing parallel to floor in neutral position and the knee is flexed more than 90 degree. Then guide wire inserted with the help of the aiming device. Drilling is done over the guide wire with $6.4 \mathrm{~mm} \mathrm{\&}$ $8 \mathrm{~mm}$ drill bit to the desired length and confirmed by $\mathrm{C}$-arm. The proximal derotation screw of $6.5 \mathrm{~mm}$ and distal lag screw of $8 \mathrm{~mm}$.Distal locking is done with self-tapping $4.9 \mathrm{~mm}$ cortical screws one in static mode and the other in dynamic mode allowing $5 \mathrm{~mm}$ dynamisation. The nail is universal with 6 degrees medio-lateral angulation and with a neck shaft angle of 135 degrees. After the fixation, thorough lavage is given with normal saline. Hemostasis is achieved and incision is closed in layers over suction drain. Sterile dressing is applied over the wound and compression bandage is given. 
2.5. Postoperative protocol and follow-up: Drain removal done by 48 hours. The epidural catheter was kept for 48 hours for postoperative analgesia. Sutures removed between 10th to 12th postoperative day. Static quadriceps exercises and knee mobilization was started in the immediate postoperative period. Non weight bearing mobilization was done in comminuted unstable fractures, but in stable fractures, partial toe touch weight bearing was started early with a walker. All patients were followed up at an interval of 4 to 6 weeks till fracture union and then once in 3 months till 1 year. At each visit, patients were assessed clinically regarding hip and knee function, walking ability, fracture union, deformity and shortening. Fresh x-rays were taken during each visit till fracture union progressive partial weight bearing was taught with help from physiotherapist up to full weight bearing.

Functional outcome of surgery was done on the basis of Anatomical results in to good or poor depending upon shortening, varus deformity, hip movements and knee movements And Functional result in to excellent, good, fair and poor depending upon the hip pain, ambulatory status, ability to squat, and sit cross leg.

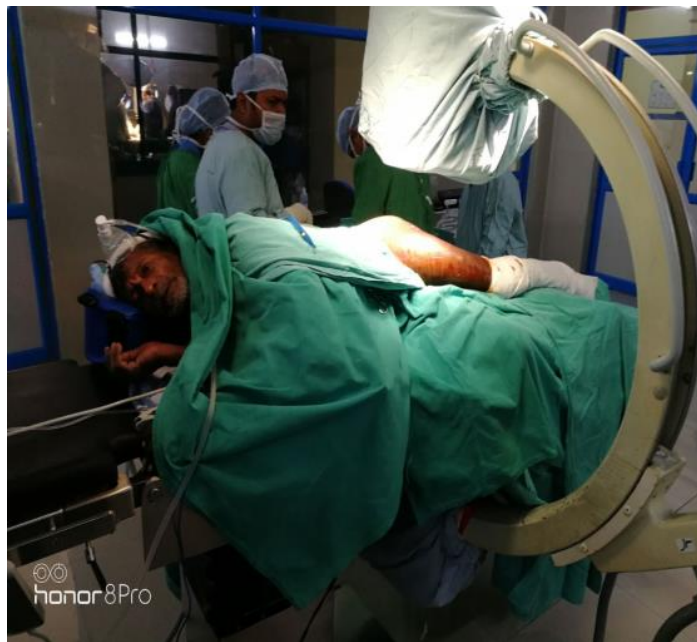

Fig 1: Patient Positioning

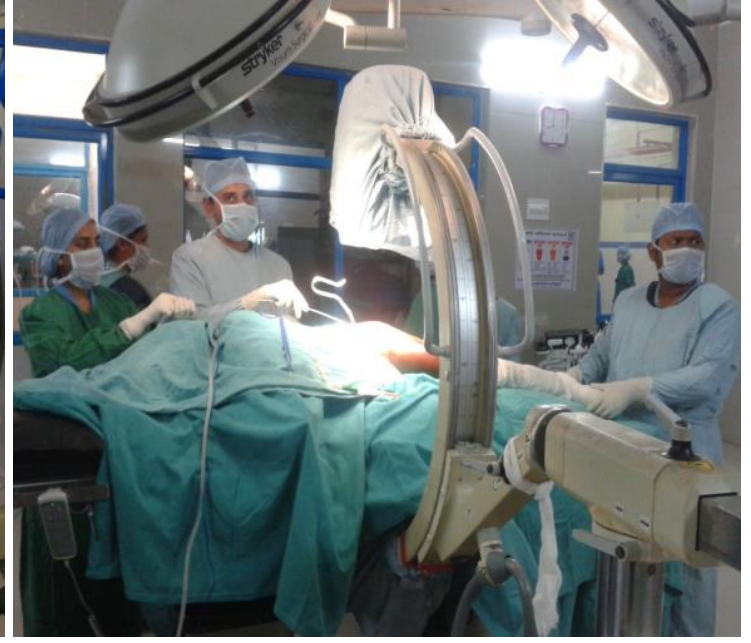

Fig 2: Insertion of Awl and Guide Wire

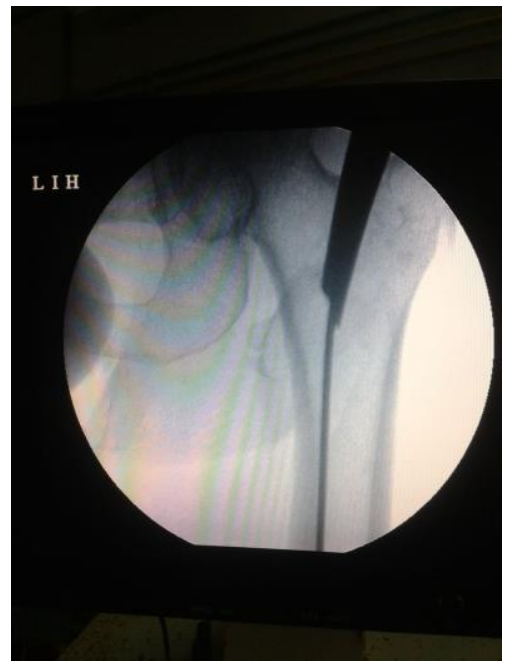

Fig 3: Entry Point \& Guide Wire

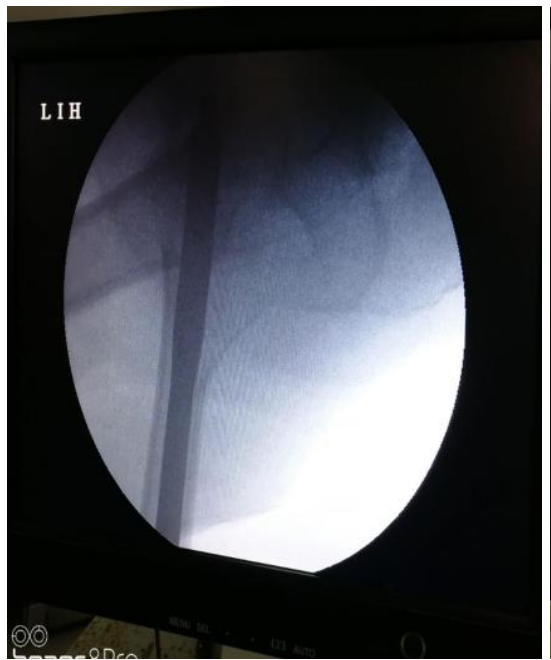

Nail Insertion

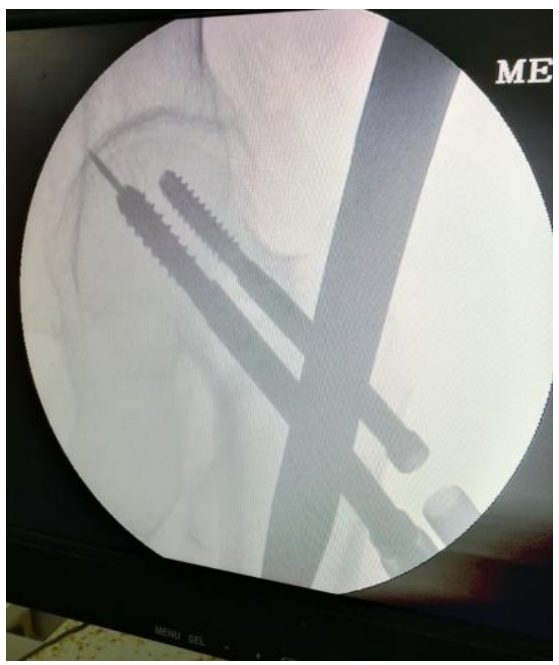

Proximal Screw Fixation

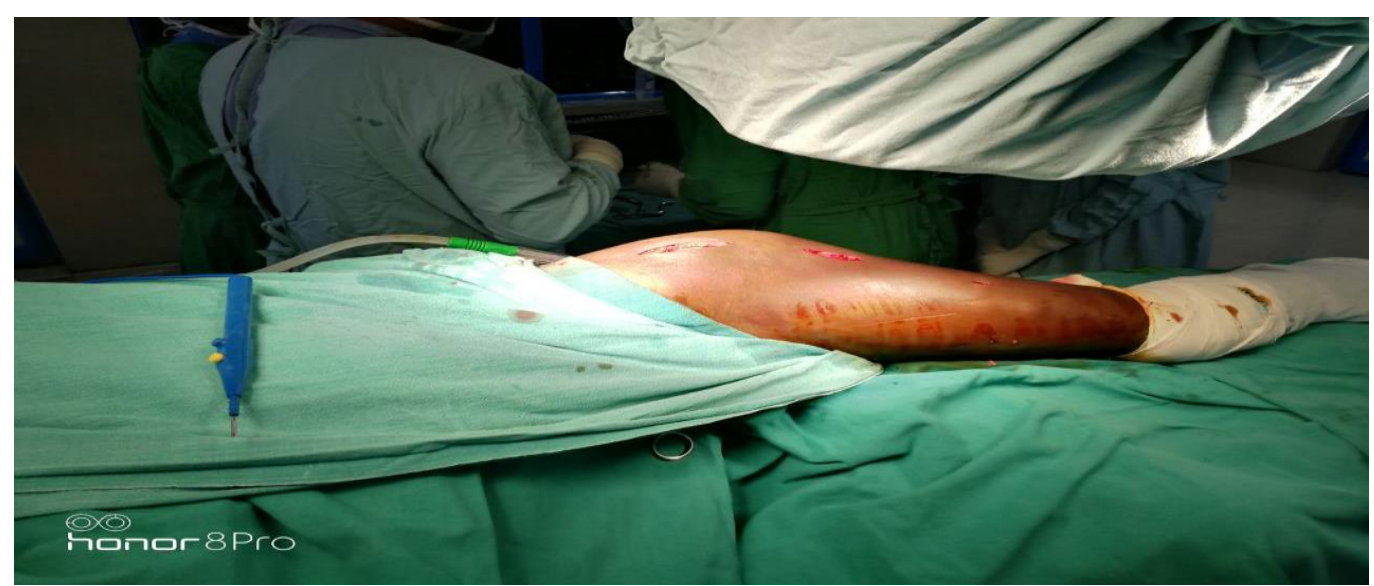

Fig 4: Incision Size 


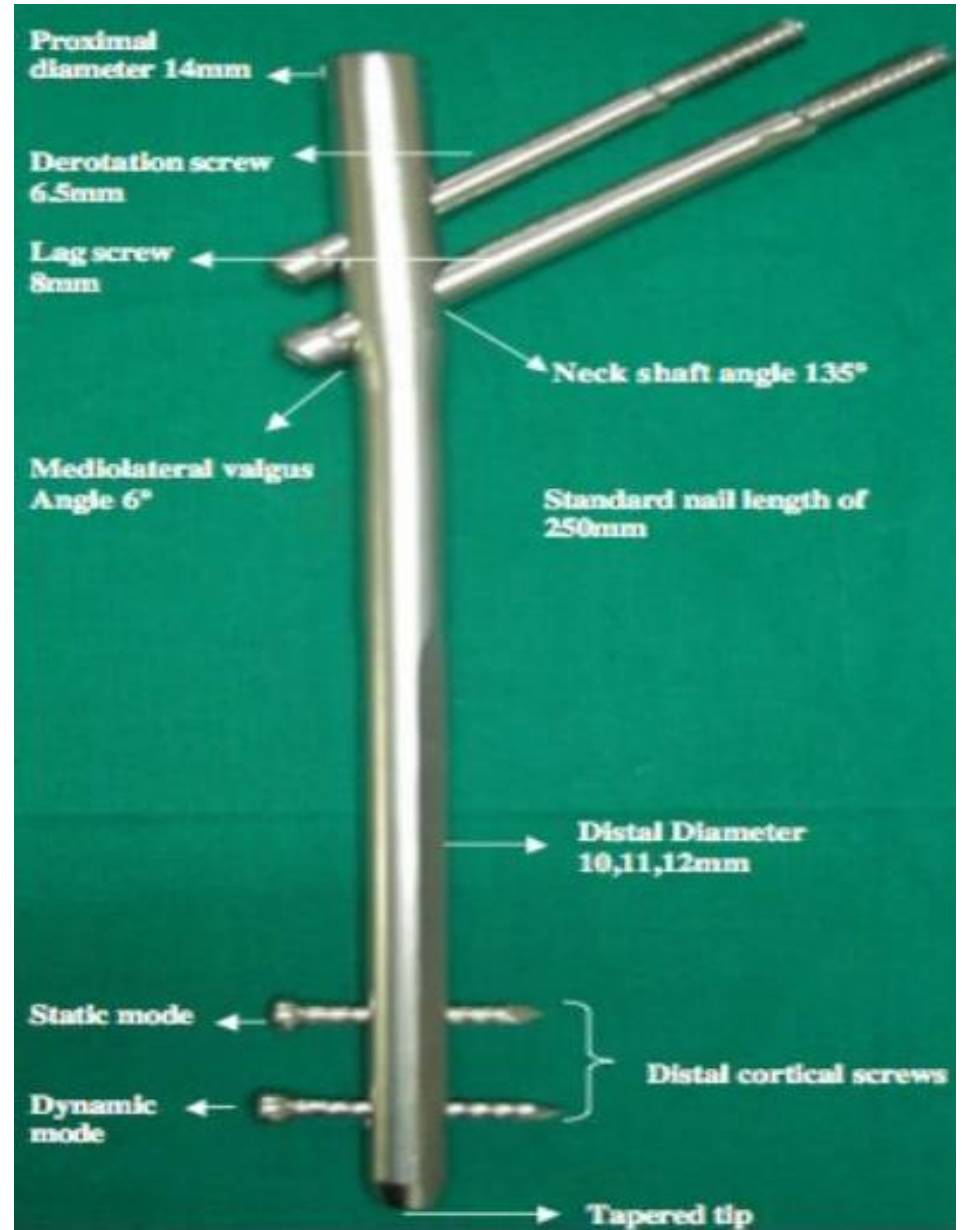

Fig 5: Geometry and Biomechanics of PFN
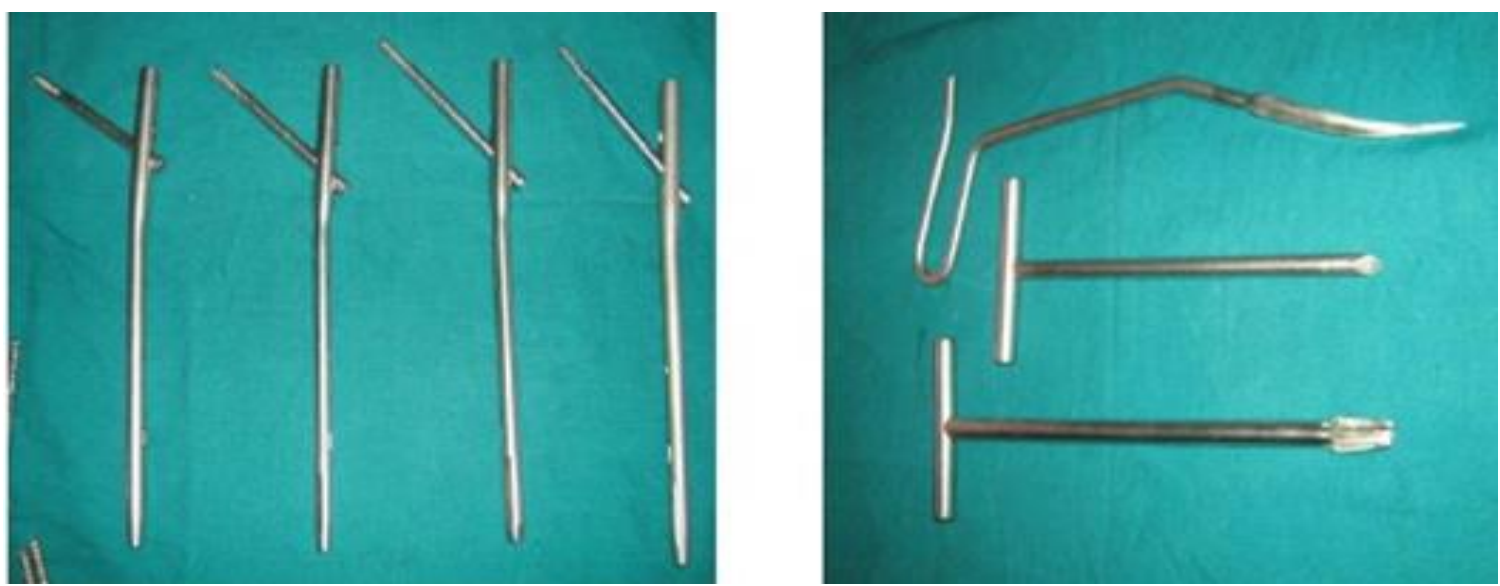

Fig 6: Various nail lengths \& instrumentation of PFN

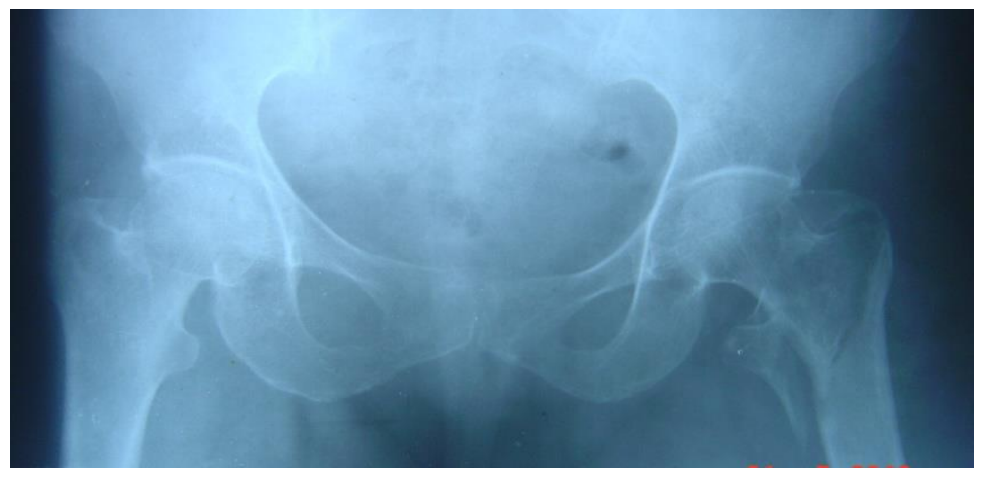

Fig 7: Pre-Operative X-ray 

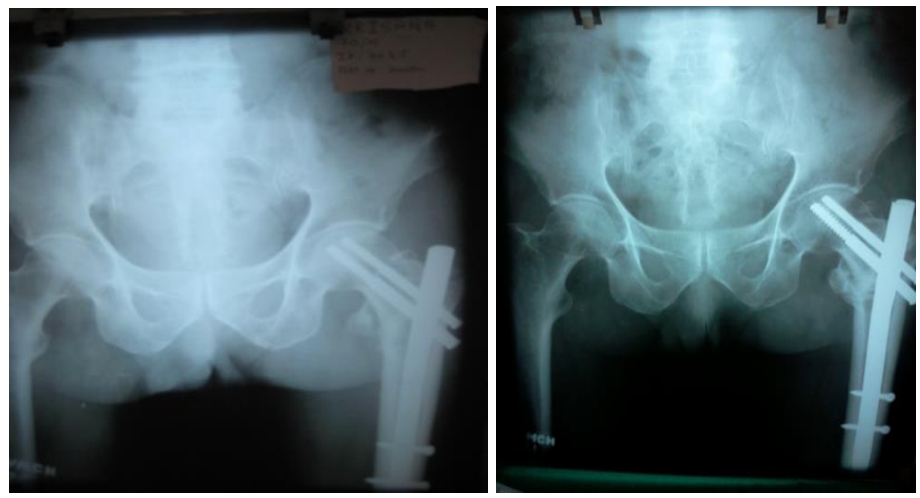

Fig 8: Immediate post-operative x-ray at 3 months follow-up

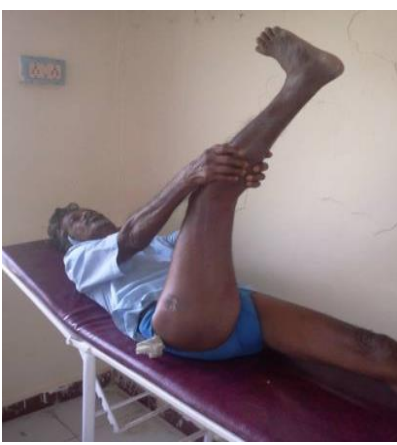

Extension

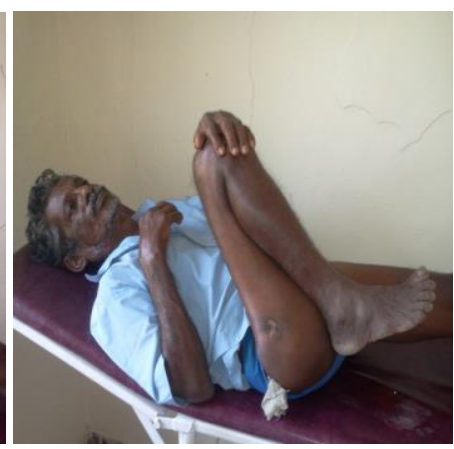

Flexion

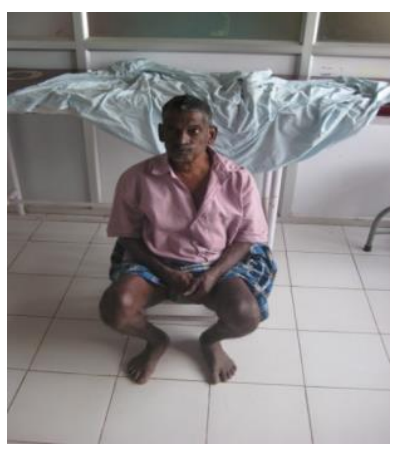

Sitting Cross Legged

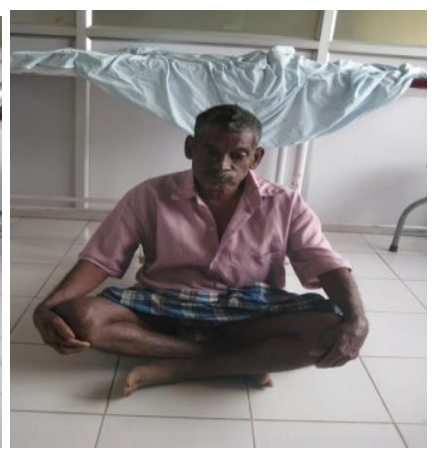

Squatting

Fig 9: Showing post-operative range of motion

\section{Results}

Most of the patients were in the age group of 60 to 78 years with mean age of 69.34 years. In this series with 30 patients 18 were males and 12 were females. This shows preponderance of males over females. Majority of Cases are due to low velocity trauma due to slip and fall injury. None of our patients had any associated bony injuries. In 16 cases left side was affected and in the remaining 14 cases, right side was affected. We used the Boyd and Griffin classification for trochanteric fractures.

All patients were operated at an average interval of 3 days from the date of trauma. An average of less than $150 \mathrm{ml}$ in closed surgery. And about $350 \mathrm{ml}$ in open reduction cases was used. Duration of surgery was considered from time of incision to skin closure. It was 60 minutes to 120 minutes mean operating time 80 minutes.

In our study, we encountered certain complications intra operatively. In 11 patients, due to comminution and posteromedial cortical void, open reduction was required. In 1 patient, there was perforation of the anterior cortex of femoral shaft due to the distal tip of the nail for which mobilization was delayed for 4 weeks. There was 1 case of drill bit breakage, which occurred while drilling for the hip pin due to mismatch in the jig. None of our patients had any significant postoperative complication. There were no wound healing problems. 2 patients developed delayed union. 3 patients with comminuted fractures and closed nailing done had shortening of $1 \mathrm{~cm}$. 1 patient had shortening of more than $1.5 \mathrm{~cm}$ due to gross comminution. 1 patient had backing out of the hip pin which required removal of the hip pin. 6 patients $(20 \%)$ had restriction of terminal hip flexion. None of our patients had knee stiffness due to the fracture and surgical procedure. Since many patients were from the elderly age group, knee osteoarthritis was present pre injury. None of our patients required bone grafting. There was no varus malunion or nonunion. There was no mortality recorded in our series till fracture union. No case of superficial or deep infection was recorded.

Table 1: Intra operative complications

\begin{tabular}{|c|c|c|}
\hline Complications & Number Of Cases & $\%$ \\
\hline Fracture Of Anterior Cortex & 01 & 03 \\
\hline Fracture Displacement By Nail Insertion & 00 & 00 \\
\hline Failure To Get Closed Reduction & 11 & 36 \\
\hline Jamming Of Nail & 00 & 00 \\
\hline Failure Of Distal Locking & 00 & 00 \\
\hline Drill Bit Breakage & 01 & 03 \\
\hline Varus Angulation & 00 & 00 \\
\hline
\end{tabular}

In our study, the average duration of hospital stay was 12.46 days. The mean time for full weight bearing was 14.2 weeks. $20 \%$ patients had 10 to 20 degree terminal restriction of hip flexion. Postoperative mobility was aided in the immediate postoperative period but later all patients were ambulatory independently with or without walking aids.

Table 2: Delayed complications

\begin{tabular}{|c|c|c|}
\hline Complications & Number of Cases & $\%$ \\
\hline Hip Stiffness & 06 & 20 \\
\hline Knee Stiffness & 00 & 00 \\
\hline Delayed Union & 02 & 06 \\
\hline Non Union & 00 & 00 \\
\hline Shortening >1 Cm & 01 & 03 \\
\hline Malunion & 00 & 00 \\
\hline Implant Failure/Screw Cut Out & 00 & 00 \\
\hline Hip Pain Back Out & 01 & 03 \\
\hline
\end{tabular}

In our study anatomical results were assessed by presence/absence of deformities, shortening, and hip and knee range of movements. And functional result was assessed by the scoring system framed by Kyle et.al overall excellent to good results were achieved in $90 \%$ cases. 
Table 3: Functional result

\begin{tabular}{|c|c|c|}
\hline Functional Results & Number of Cases & \% \\
\hline Excellent & 21 & 70 \\
\hline Good & 06 & 20 \\
\hline Fair & 03 & 10 \\
\hline Poor & 00 & 00 \\
\hline
\end{tabular}

\section{Discussion}

Davis et al. in 1969 used the lateral position as a facilitated position for reduction and exposure for the first time in intertrochanteric and subtrochanteric fractures of the femur, Ozkan et al. used this position in proximal femoral nailing in 2010 and Connelly et al. in complex proximal femur locked plating in $2012^{[14-16]}$. In our study minimal surgical incision good reduction and alignment of fracture in lateral position, hemostasis, and decreased surgery time and less radiation of C-arm was observed.

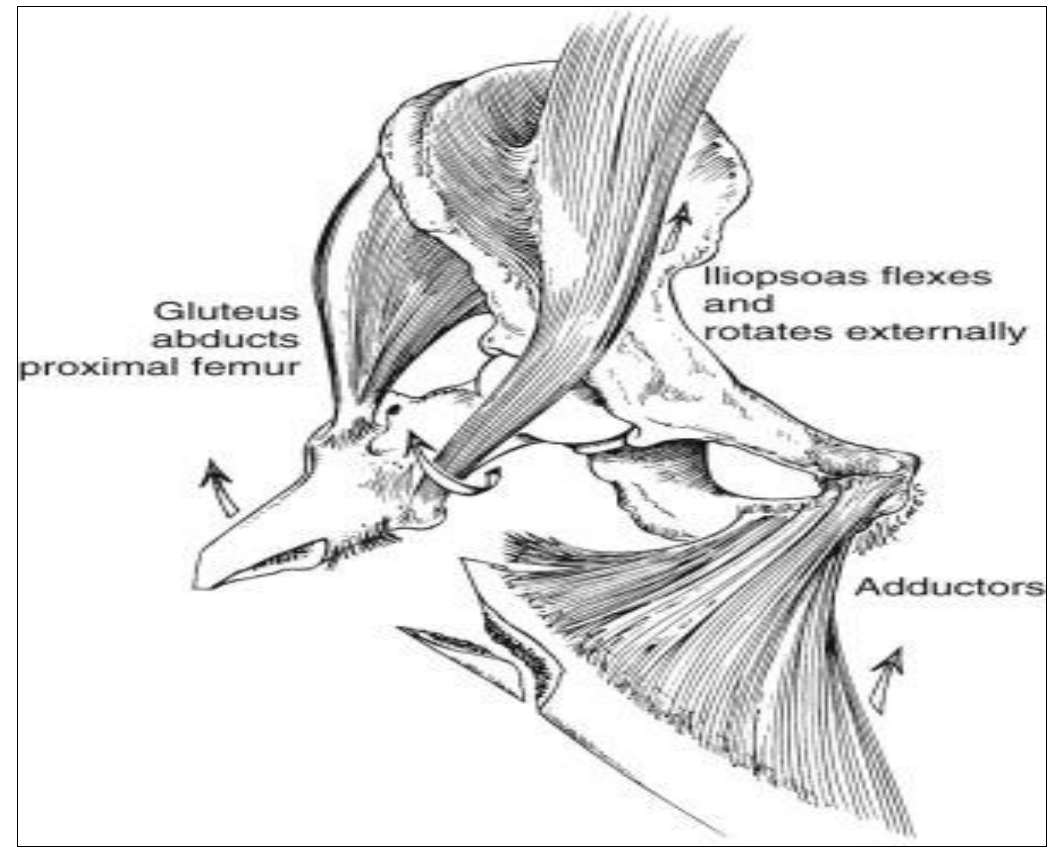

Fig 10: Lateral position as a facilitated position for reduction and exposure for the first time in intertrochanteric and subtrochanteric fractures of the femur

4.1. Problems in Supine Position on A Fracture Table: In Sub-trochanteric, and high sub-trochanteric femur fractures, proximal segment is flexed \& abducted due to pull of strong muscles around the hip. Obesity/pendulous sagging abdomen makes entry of awl in proximal femur (pyriformis fossa) guide wire passing reaming difficult and obstructs insertion of PFN nail and jig assembly. Osteoarthritic knees with flexion deformity of knee causes sagging of shaft portion of femur making entry difficult as well as negotiation of guide wire reamer and nail in distal segment. $\mathrm{C}$-arm adjustments have to be made number of times to check in AP/Lateral views by moving the heavy body of $\mathrm{C}$-arm machine. As the operative thigh has to be adducted for having a good entry in pyriformis fossa there is limited and constrained space for moving $\mathrm{c}$ arm and adjusting the $\mathrm{c}$ arm between the two legs of the patient. Lateral view of neck is difficult to visualize with adducted operative limb. As the foot of patient is tied at the footplate of fracture table, manipulation of displaced small and large comminuted fragments and segment is difficult. In case of difficulty if fracture needs open reduction the soft tissues and muscles are severely stretched in traction on fracture table not allowing the surgeon to manipulate the segments easily. Secondly haemostasis achievement also becomes difficult.

4.2. Advantages in Lateral Position: In lateral position, all muscles around hip are relaxed. Affected limb is freely draped to have free movement. Distal segment can be mobilized to align with proximal segment freely with gentle longitudinal traction holding the knee or leg. In lateral position proximal segment can be manually pushed to get good adduction \& have a easy access in pyriformis fossa (entry point). A further procedure i.e. awl insertion, negotiation of distal canal for reaming \& nail insertion becomes easy. C-arm remains stationary showing AP view as patient is lying in lateral position. $\mathrm{C}$-arm adjustment is not required to view AP/Lateral views. Visualization of Lateral view of neck Femur is possible by just flexing \& abducting and mild external rotation of limb to see guide wire/proximal screws in neck/head without moving the heavy machine body. In case the operating theatre is small the $\mathrm{C}$ arm along with fracture table is occupying much space so in such situation, the $\mathrm{C}$ arm can be adjusted in Scorpion flanges position such that the $\mathrm{C}$ arm is horizontally aligned from foot end and can be adjusted accordingly.

The possibility of distal interlocking with distraction at fracture site is more in operating on fracture table with fixed traction, whereas this possibility is not present as all muscles are relaxed in lateral position. Muscular forces around hip in sagittal plane (Hip flexors and extensors) are more effectively neutralized in lateral position where as the coronal plane forces (Abductors and Adductors) are easily neutralized with a firm pillow between two legs in lateral position ${ }^{[16]}$.

In present study, average of less than $150 \mathrm{ml}$ in closed surgery and about $350 \mathrm{ml}$ in open reduction cases, blood lost. It was showed in this meta-analysis that surgery in lateral decubitus was marginally associated with less blood loss compared with surgery in supine position ${ }^{[17]}$.

There were some limitations in our study firstly, lack of a control group made the comparisons of minimal surgical incision reduction and alignment of fracture in lateral position, hemostasis, and decreased surgery time and less radiation of C-arm are impossible. Secondly, we did not use 
an accepted outcome measure instrument for evaluation of the patients' ability to squat and walk with no limp for assessing outcome was also a crude method. But assessment for bony union with serial radiographs in our study was acceptable.

Nailing of the femur can be performed in both supine and lateral position. The supine position is physiologic and convenient to the anesthetist and is preferred if patients also have cervical spine injury, ipsilateral lower extremity fracture and severe pulmonary compromise. But access to greater trochanter is somewhat limited in supine position, particularly in large or obese patients in whom lateral position is preferred [18-19]. Thus, lateral positioning obviates the need for a fracture table, makes it easier to establish a starting point for an intramedullary device, and facilitates conversion to an open procedure without repositioning should this become necessary. In the present study, we designed the lateral decubitus position PFN and investigated and compared the clinical results and complications of PFN in the treatment of elderly intertrochanteric fracture patients. These patients were placed in the lateral decubitus position on the flat radiolucent table, and the healthy limb maintained flexion of their hip and knee during the surgical operations in order to obtain the lateral hip X-ray photos. Under anesthesia and muscle relaxation conditions, the manual traction was operated in order to restore fractures and will avoid the complications caused by the use of the fracture table, such as pudendal, sciatic and femoral nerve palsy, perineal sloughs, well leg compartment syndromes, avulsion of the inferior epigastric artery in the contralateral limb, and crush syndromes ${ }^{[20]}$. The present results suggested that only one patient developed a superficial wound infection in the lateral decubitus position group. Compared with the supine position group, once surgical operation achieved restore fractures in the lateral decubitus position group. Most of intertrochanteric fractures are low-energy osteoporotic fractures, and primary injuries of soft tissue are lighter.

The advantages of the lateral decubitus position group also mainly included sustained traction, mild adduction, and internal rotation bit of hips, as well as without obvious shift performance of restore fracture. Of course, PFN with the lateral decubitus position also has some limitations on the treatments of intertrochanteric fractures in the elderly patients, who cannot tolerate the lateral decubitus position. Moreover, some patients have some complications, such as spine unstable fractures, severe lung damage disease, and contralateral lower extremity fractures, who are not suitable for the lateral decubitus position.

\section{Conclusion}

The potential advantages of the Proximal Femoral Nail over extramedullary devices is minimal invasiveness due to closed technique, minimal soft tissue dissection, better biomechanical design to prevent implant failure and ability to bear more load as it is load bearing implant and decreased abductor lever arm.

The advantage of lateral position over supine position is easy identification of greater trochanter and entry point, useful in obese patients, easy to achieve reduction by open reduction technique and ease in placing distal locking screws. The lateral decubitus position also provides a shorter operation time, less of hospital stay, blood loss, number of intraoperative X-ray, incision length and out-of-bed activity time. Reduction and fixation of proximal femoral fractures in the lateral position with fluoroscopy in the antero-posterior view for small set ups or in rural hospitals that lack a fracture table or advanced fluoroscopic devices may be executable and probably safe. Therefore, PFN fixation in the lateral decubitus position may be considered a better choice for the treatment of peri-trochanteric fractures in the elderly patients.

\section{References}

1. Dimon III, Joseph H, Jack Hughston C. Unstable intertrochanteric fractures of the hip. JBJS. 1967; 49(3):440-450.

2. Chang WS, Zuckerman JD, Kummer FJ, Frankel VH. Biomechanical evaluat ion of anatomic reduction $\mathrm{v} / \mathrm{s}$ medial displacement osteotomy in unstable intertrochanteric fractures. $\mathrm{Cl}$ in Orthop. 1998; 225:1456.

3. Karn NK, Ashish Jain, Mahi Pal Singh. A Prospective Randomized Control Trail Comparing Proximal Femoral Nail and Sliding Hip Screw in The Management of Trochanteric Fracture of The Femur. Health Renaissance. 2011; 9:7-1.

4. Hutchings L, Fox R, Chesser T. Proximal femoral fractures in the elderly: how are we measuring outcome? Injury. 2011; 42(11):1205-1213.

5. Zeng C, Wang YR, Wei J et al. Treatment of trochanteric fractures with proximal femoral nail antirotation or dynamic hip screw systems: a meta-analysis. Journal of International Medical Research. 2012; 40(3):839-851.

6. Nork SE, Reilly MC. Skeletal Trauma. 4th ed. Philadelphia, PA: WB Saunders; Subtrochanteric fractures of the femur, 2008, 1977-2034.

7. Horwitz T. The posterolateral approach in the surgical management of basilar neck, intertrochanteric and subtrochanteric fractures of the femur; a report of its use in 36 acute fractures. Surgery, gynecology \& obstetrics. 1952; 95(1):45-50.

8. Davis PH, Frymoyer JW. The lateral position in the surgical management of intertrochanteric and subtrochanteric fractures of the femur. J Bone Joint Surg Am. 1969; 51(6):1128-34.

9. Rohilla R, Singh R, Rohilla S, Magu NK, Devgan A, Siwach R. Locked intramedullary femoral nailing without fracture table or image intensifier, Strategies in Trauma and Limb Reconstruction. 2011; 6(3):127-135.

10. Kim KJ, Choy W-S, Lee SK, Park HJ. Closed femoral intramedullary nailing in the lateral decubitus position with the aid of intraoperative skeletal traction, European Journal of Orthopaedic Surgery and Traumatology. 2012; 22(6):481-485.

11. Camille Connelly L. J Orthop Trauma. 2012; 26(4):252257.

12. Anatomic Reduction and Locking Plate Neutralization: A Technical Trick. Journal of Orthopaedic Trauma. 2012; 26(4):252.

13. Callanan I, Choudhry V, Smith H. Perineal sloughing as a result of pressure necrosis from the traction post duringprolonged bilateral femoral nailing. Injury. 1994; 25(7):472.

14. Davis PH, Frymoyer JW. The lateral position in the surgical management of intertrochanteric and subtrochanteric fractures of the femur. J Bone Joint Surg Am. 1969; 51(6):1128-34.

15. Ozkan K, Cift H, Akan K, Sahin A, Eceviz E, Ugutmen E. Proximal femoral nailing without a fracture table. European Journal of Orthopaedic Surgery \& Traumatology. 2010; 20(3):229-31.

16. Camille Connelly L. J Orthop Trauma. 2012; 26(4):252- 
257.

17. Müller M. CCF-Comprehensive Classification of Fractures I \& II. MEM üller Foundation. Bern: MAO/ASIF Documentation Center; Lin J Encouraging results of treating femoral trochanteric fracture, 1996, 16.

18. Wolinsky PR, McCarty EC, Shyr Y, Johnson KD. Length of operative procedures: reamed femoral intramedullary nailing performed with and without a fracture table. Journal of Orthopaedic Trauma. 1998; 12(7):485-495.

19. Aiyer S, Jagiasi J, Argekar H, Sharan S, Dasgupta B. Closed antegrade interlocked nailing of femoral shaft fractures operated up to 2 weeks postinjury in the absence of a fracture table or C-arm. Journal of Trauma. 2006; 61(2):457-460.

20. Haddad FS, Cobiella CE, Wilson L. Inferior epigastric artery avulsion: a fracture table complication. Journal of Orthopaedic Trauma. 1998; 12(8):587-588. 